\title{
Carne e espelho em Merleau-Ponty
}

\author{
Emmanuel de Saint Aubert \\ e.dsta@free.fr
}

CNRS, ENS, Archives Husserl de Paris, Paris, França

resumo Entrelaçada com estruturações naturais e história pessoal, a carne, na concepção gradualmente forjada por Merleau-Ponty, é nutrida pelas influências combinadas da neurologia, Gestalt psicologia e psicanálise. Essa tripla influência sustenta um tema recorrente em seus últimos escritos: o espelho. "A carne é um fenômeno de espelho", nos diz Merleau-Ponty. Os manuscritos não publicados revelam que esta famosa sentença não se refere diretamente a Husserl, nem a Wallon e Lacan, mas é conduzida pelas leituras contemporâneas de Paul Schilder e Wolfgang Metzger, que estudam o fenômeno de migrações distanciadas da imagem corporal na visão. 0 espelho mistura corpo objetivo e corpo fenomenal, em uma comunidade efetiva entre meu corpo vivido e sua imagem externa. Ele mostra como a carne vive tanto em si quanto fora de si, animada por uma incompletude essencial que envolve a percepção em um processo de incorporação e, consequentemente, aponta para a intercorporeidade.

palavras-chave carne; espelho; imagem corporal; percepção; intercorporeidade.

Tecida pelas estruturações naturais e pela história pessoal, a carne, na concepção que Merleau-Ponty forja progressivamente, é nutrida pela influência cruzada da neurologia do esquema corporal, da psicologia da forma e da psicanálise da incorporação: esta tripla influência sustenta um tema recorrente nos últimos escritos, o espelho. Aqui, abordaremos esse tema sem submetê-lo a um tratamento exaustivo, deixando de lado certas fontes para privilegiar aquilo que constitui, a nosso ver, o ângulo principal de ataque da questão nos manuscritos tardios.

Recebido em 20 de dezembro de 2011. Aceito em 14 de fevereiro de 2012.

Traduzido por Alex de Campos Moura.

doispontos, Curitiba, São Carlos, vol. 9, n. 1, p.11-33, abril, 2012 
Uma nota pessoal de maio de 1960 comporta uma destas afirmações fortes que soam como definições da carne: "A carne é fenômeno de espeIho" ${ }^{1}$. Esta famosa proposição pode ter parecido reenviar à generalização, por Merleau-Ponty, do tocante-tocado (husserliano) ao vidente-visível (não-husserliano), ou ainda a uma reminiscência do Estádio do Espelho de Lacan. Assim como várias outras fórmulas elípticas dos últimos escritos, ela pertence a um texto que o autor escreveu para si mesmo e não para nós, e vem cristalizar uma reflexão de momento, sem que Merleau-Ponty tivesse necessidade de anotar as referências subjacentes. Nós somos facilmente enganados por estas edições póstumas que lemos, espontaneamente demais, a partir de nossa cultura comum sobre a filosofia do autor, sem antes investigar a possível novidade ou originalidade destes mesmos textos - os documentos de trabalho, o que significa que Merleau-Ponty não está necessariamente repetindo aquilo que, de outra forma, já está estabelecido em sua obra publicada.

Leiamos a frase até o final: "A carne é fenômeno do espelho e o espelho é extensão de minha relação com meu corpo". No caso preciso, os inéditos revelam que esta afirmação é habitada pelas leituras contemporâneas de Wolfgang Metzger e, mais ainda, de Paul Schilder (típico do cruzamento merleau-pontyano entre neurologia, Gestalttheorie e psicanálise). Ligando-se às outras proposições elípticas vizinhas, ela é sustentada por uma reflexão sobre dois fenômenos marcantes analisados por estes autores, dois exemplos da migração à distância do esquema corporal na percepção. $\mathrm{O}$ espelho embaralha corpo objetivo e corpo fenomenal, em uma comunidade efetiva entre meu corpo vivido e sua imagem "exterior". Ele "leva para fora os segredos de minha carne", e esta presença à distância reveste, do mesmo modo, as coisas percebidas de "todo o invisível de meu corpo": eu lhes empresto minha carne, "os outros são feitos de minha substância"2. O espelho revela assim que a carne sempre vive ao mesmo tempo aqui e lá, tanto dentro como fora de si mesma, mas também que ela tem necessidade "de se relacionar com outra coisa que sua própria massa" 3 , demanda uma outra carne para existir. O espelho exprime o inacabamento essencial da carne, que engaja em toda percepção um trabalho de incorporação e, por isso mesmo, um esboço de intercorporeidade. 


\section{$\S 1$. Entre Wallon et Lacan}

Antes de abordar Metzger e Schilder, e para estar em condição de lhes apreciar a contribuição original, voltemos rapidamente às primeiras reflexões de Merleau-Ponty sobre o espelho. Estas tiveram origem nos cursos da Sorbonne, em particular na primeira parte do curso sobre Les relations avec autrui chez l'enfant (1950-1951). Os trabalhos de Henri Wallon são aqui decisivos, em particular sua obra sobre Les origines $d u$ caractère chez l'enfant (WALLON 1934) ${ }^{4}$. Esta leitura mostra a MerleauPonty quanto o esquema corporal é de início investido por outros esquemas posturais, fenômeno que a experiência do espelho revela em seu mais alto grau. Conhecemos melhor hoje em dia a dívida do Estádio do Espelho de Lacan em relação a Wallon ${ }^{5}$. Merleau-Ponty, que aprecia este último por sua atenção ao sentido próprio da vida da criança - e que o segue largamente em sua crítica a Piaget -, conhecia suas ideias antes de ler Lacan. Os cursos da Sorbonne também expõem longamente sua abordagem sobre o espelho, lhe dando mais espaço que à de Lacan ${ }^{6}$.

A "prova do espelho" é um rito de passagem que permite progressivamente à criança integrar e unificar seu corpo no espaço ${ }^{7}$. Esta unificação passa pelo outro, na medida em que a criança não tem acesso à imagem de si a não ser após aceder àquela do outro. Pelo corpo de outrem, a criança dispõe de duas experiências visuais concordantes, aquela da visão direta e aquela do espelho. O que não é o caso para seu corpo próprio: apenas a imagem do espelho lhe propõe um domínio do conjunto, bem além de sua capacidade de enxergar diretamente tais ou tais partes de seu corpo. É por isso que a criança começará por experimentar a imagem especular como uma espécie de duplo de seu corpo verdadeiro, e por viver assim um fenômeno de ubiquidade, comportando-se como certos doentes acometidos por problemas heautoscópicos. Ele terá que compreender que a imagem visual de seu corpo que ele vê, lá, no espelho, não é ele; depois compreender que, não estando localizado lá, mas onde ele se sente pela interoceptividade, ele é contudo visível para outrem sob o mesmo aspecto que aquele que lhe oferece o espelho. A criança tem então que ultrapassar a imagem especular, para reenviá-la, do lugar que ocupa no fundo do espelho, até ela, e assim ser capaz de se identificar, a partir daí, à distância com seu corpo interocep- 
tivo. Chegando a este ponto, ela terá fechado sobre si um círculo que, de passagem, passou por outrem. Como veremos em breve, este movimento do conjunto - que passa da imagem exterior ao corpo interoceptivo - é o inverso daquele que aprofundarão os últimos escritos de MerleauPonty sobre o espelho - que privilegiarão os processos de projeção do dentro no fora, o deslocamento da minha carne sobre a imagem exterior. Estas descrições não são contudo contraditórias, mas simétricas e complementares.

Esta problemática geral da unificação do corpo próprio é ainda aquela do Estádio do espelho de Lacan: “Trata-se desta representação narcísica que tentei expor no congresso internacional falando do 'Estádio do Espelho'. Esta representação explica a unidade do corpo humano; por que esta unidade deve se afirmar? Precisamente porque o homem sente mais dolorosamente a ameaça da fragmentação" 8 . A releitura lacaniana da prova do espelho, vista a algumas linhas, é mais dramática que aquela de Wallon. Após o nascimento, a criança experimenta a falta de domínio tônico e motor de seu corpo, e não pode ainda aprendê-lo como uma unidade orgânica. As experiências heterogêneas, discordantes, se sucedem, e esta ausência de ligação induz, sobre um fundo de "angústia original”, a experiência fantasmagórica do corpo fragmentado. Antes mesmo que uma maturação suficiente permita a plena coordenação das atividades orgânicas, um modelo de unidade já se propõe, contudo, ao seu olhar: a imagem global do corpo próprio que ele descobre no espelho. O "Estádio do Espelho" se ordena então sobre uma experiência de identificação fundamental no curso da qual a criança efetua a conquista de imagem de seu corpo próprio ${ }^{9}$. Esta identificação promove a estruturação do Eu neutralizando em parte a dispersão angustiante do corpo, o espectro da fragmentação.

Mas a liberação não é jamais total, o nível de desintegração agressivo mantém seus vestígios e continua a ameaçar e unidade do Eu (LACAN 1966, p.94 $)^{10}$. Diante de sua imagem, a criança ao mesmo tempo alegrase e conhece um mal-estar profundo: sua relação consigo mesma será sempre marcada por esta ambivalência. E não se trata aí do simples fato de um processo inacabado: pelo espelho, a unificação se faz juntamente com a alienação, a criança se identifica à forma vista mesmo não sendo esta forma, a imagem é ao mesmo tempo a dela e a de um outro, ela se identifica se alienando. $\mathrm{O}$ eu forja assim sua unidade em uma captura, expe- 
riência que não cessará de projetar sua sombra na relação da criança com todas as coisas.

Enquanto Wallon estava atento sobretudo à unificação do esquema corporal, Lacan insiste também sobre a dispersão angustiante, ameaçada por sua fragmentação, o fato da equivocidade identitária. Passando de um a outro, deixamos a espacialidade de inerência de Wallon - espacialidade de fixação e de indivisão que marca Merleau-Ponty - por uma forma mais complexa e dialética de estruturação do espaço carnal e identitário, que guarda para sempre traços da heterogeneidade originária das experiências sensoriais e motoras, assim como da alienação vivida no coração mesmo da identificação.

As primeiras referências de Merleau-Ponty ao pensamento de Lacan aparecem imediatamente após a publicação, no final de 1949, da comunicação sobre "O Estádio do Espelho como formador da função do Eu". Como destaca Émile Jalley, Merleau-Ponty é sem dúvida o primeiro filósofo a comentar as concepções de Lacan sobre a imagem especular (JALLEY 1998, pp.38-39) ${ }^{11}$. Ele o faz em diversos momentos no curso da Sorbonne ${ }^{12}$, utilizando de imediato o texto de 194913, o artigo sobre "A família” redigido para a Encyclopédie française, assim como «Formulações sobre a causalidade psíquica». Merleau-Ponty se debruça então sobre o essencial daquilo que Lacan já havia publicado sobre a questão. Ele reencontra aí certas linhas de sua filosofia da existência, em particular a coesão frágil da carne e as ameaças da transgressão ${ }^{14}$, o espelho permitindo tão bem o fechamento narcísico quanto a intrusão do outro ${ }^{15}$. Nossa relação complexa com o espelho envolve a tensão da regressão e da antecipação, da circularidade e da transgressão, e assim faz eco ao forro topológico paradoxal de uma carne envolvida e aberta, à sua dupla orientação perpétua em direção ao passado e ao futuro - tantos dos traços que vão caracterizar a carne merleau-pontyana. Opor narcisismo e abertura à outrem, circularidade e transgressão, seria retornar ao dualismo do narcísico oposto ao objetal; o que seria, justamente, deixar de lado a riqueza da exploração lacaniana do mito de Narciso.

Merleau-Ponty não deixa de apreciar o modo pelo qual Lacan, em seu texto de 1949, introduz o Estádio do Espelho em uma denúncia vigorosa das filosofias da consciência em geral, e em particular do existencialismo sartriano. Ele encontra aí uma cumplicidade com sua 
própria crítica contemporânea da psicanálise existencial ${ }^{16}$ e, de modo mais amplo, com sua filosofia nascente da carne - aquela que em breve consagrará L'homme et l'adversité ao se apoiar justamente sobre a psicanálise. Entretanto, em razão mesmo dessa cumplicidade, a leitura de Merleau-Ponty é já orientada, e não leva em consideração toda a extensão da novidade da abordagem lacaniana. Ainda que critique a interpretação do espelho de Wallon como sendo cognitiva demais, e mesmo se menciona a dimensão de alienação implícita pelo Estádio do Espelho, Merleau-Ponty resume a contribuição de Lacan a um desenvolvimento da significação afetiva e imaginária deste estado ${ }^{17}$, parecendo esquecer, de passagem, a violência de sua dimensão simbólica. Não é senão mais tarde, por uma outra mediação - aquela de Paul Schilder - que ele evocará, por sua vez, uma forma de negatividade que assombraria os fundamentos mesmos da imagem do corpo.

\section{§ 2. 0 dado de arame revestido da minha carne}

Depois do curso Les relations avec autrui chez l'enfant, Merleau-Ponty não fala mais do espelho em relação explícita com Lacan, exceto por uma simples menção do Estádio do Espelho em Le monde sensible et le monde de l'expression $(1953)^{18}$. Este mesmo curso, pelo tratamento inovador de seu tema principal - a expressão - prepara a fenomenologia para uma reflexão totalmente diversa sobre o espelho. Merleau-Ponty de fato empreende aí uma análise audaciosa da percepção do movimento como implicando um investimento imaginário radical, uma verdadeira "projeção antropológica"19 $^{19}$, direção teórica que vai desempenhar um papel importante em seus desenvolvimentos tardios sobre o espelho em relação com a carne.

Quando Merleau-Ponty escreve em maio de 1960 que "a carne é fenômeno de espelho e o espelho é extensão da minha relação com meu corpo", ele se apoia de início em uma leitura que o absorve profundamente durante os meses de abril e maio do mesmo ano. Trata-se da segunda edição de Gesetze des Sehens, estudo volumoso de Wolfgang Metzger ${ }^{20}$ sobre a percepção visual, tornado uma referência clássica da Gestaltheorie. Encontramos sobre ele longas notas de leitura, no volume mais tardio do projeto de Être et Monde ${ }^{21}$. 
Metzger descreve aí o seguinte dispositivo ${ }^{22}$. Após ter fabricado uma armação de dado em arame e tê-la fixado na ponta de uma haste, ele projeta uma sombra precisa sobre uma parede, e gira a haste entre os dedos. Para grande surpresa do autor, a sombra assume a aparência de um corpo real que se move e cuja forma se mantém constante 23 . O movimento retira a sombra de seu estatuto de imagem projetiva e a metamorfoseia em corpo vivo: a sombra se faz carne ${ }^{24}$. A título de verificação, Metzger refaz a experiência com uma forma não geométrica, um arame deformado sem qualquer regularidade: o resultado é idêntico. Em seguida, ele retoma a amação cúbica e a coloca diante de um espelho, de modo que a imagem do dado de arame apareça, do seu ponto de vista, no centro do dado real. Metzger então gira novamente a haste, e após alguns instantes se produz uma ilusão visual de encarnação que o espanta ainda mais que as experiências precedentes: a imagem, a seus olhos, se desprende da superfície do espelho e vem se colocar diante dele, no lugar do cubo real; mais surpreendente ainda, ela gira na mesma direção que este último, ainda que ela seja objetivamente invertida pelo espelho ${ }^{25}$. Novamente, o movimento metamorfoseia o inspectio mentis da representação projetiva em uma visão total, onde meu corpo motor empresta sua carne para o esqueleto de ferro.

A leitura desses conceitos extraídos da experiência renova a análise da presença carnal do cubo, que a Phénoménologie de la perception retomava da teoria husserliana dos esboços ${ }^{26}$. Merleau-Ponty descobre em Metzger o dispositivo extremo de um cubo objetivo, materialmente e estruturalmente reduzido à sua essência geométrica (uma armação em arame), que, pelo movimento, se torna um corpo fenomenal, se faz carne ${ }^{27}$. O exemplo é preciso, pois ele não se inscreve mais no molde puramente fenomenológico de um cubo pré-objetivo, inelutavelmente destinado a dar lugar a seu estado projetivo, mas no molde ontológico de uma concepção do real onde o objetivo permanece sempre misturado com a carne. Mesmo esse cubo reduzido a sua armação em arame - portanto reconduzido ao mais próximo de sua essência geométrica absoluta - se reveste de carne, tão logo lhe damos movimento 28 .

Este exemplo do que é menos carnal, ao qual o menor movimento refaz carne, está nos antípodas da densidade evocada por Sartre para ilustrar sua própria concepção da carne: o ser aparentemente mais 
carnal, do qual é preciso retirar todo movimento para lhe extrair a carne $^{29}$. Ele dá também a Merleau-Ponty uma considerável ilustração da ideia segundo a qual o real é tecido pelo imaginário, na linha dos devaneios bachelardianos ${ }^{30}$. Ele nos introduz, enfim, ligada a essa mesma ideia, à concepção original da doação carnal, em direção à qual se orientam os últimos escritos.

\section{$\S 3$. Sentir seu charuto no espelho}

A atenção dada por Merleau-Ponty a estas experiências de Metzger é redobrada, ao mesmo tempo, por uma outra leitura: aquela do impressionante Paul Schilder, neuropsiquiatria vienense exilado nos Estados Unidos, autor princeps sobre o esquema corporal na primeira metade do século XX, doutor em filosofia, dotado de um conhecimento profundo da Gestaltheorie, mas também dos trabalhos de Husserl e de Freud. Não é aqui o lugar de retomar a influência determinante de Schilder sobre a concepção merleau-pontyana da carne ${ }^{31}$. Esta influência assume toda sua importância a partir do curso de 1953 sobre Le monde sensible et le monde de l'expression, e chega ao auge na primavera de 1960 com as lições do Collège de France sobre o corpo humano. Em Notes sur le corps (inéditos), várias folhas preparam os cursos de março de 1960 e fazem referência à reflexão que Schilder consagra ao espelho em sua obra principal, The Image and Appearance of the Human Body ${ }^{32}$. Esta referência se estenderá em L'Oeil et l'Esprit, escrito durante o verão seguinte, e mesmo no curso de 1961 sobre a ontologia cartesiana. As notas sobre o espelho de Metzger, tomadas entre abril e maio de 1960, são assim encadeadas e acompanhadas pela leitura de Schilder.

Se a retomada de Metzger contribui para mostrar que o tratamento merleau-pontyano tardio do espelho não é um alargamento ao visívelvidente do tocante-tocado husserliano ${ }^{33}$, a reflexão em torno de Schilder prova que este mesmo tratamento também não é uma retomada direta de Wallon e Lacan. Em contrapartida, podemos considerar que a leitura de Schilder por Merleau-Ponty faz convergir estas diversas influências em sua concepção da carne e da intercorporeidade. Ela marca sua reflexão última sobre o vidente-visível, e contribui na difícil noção de "generali- 
dade carnal" - extensão da minha relação com meu corpo, o espelho, que "traga para fora minha carne" 34 , é instrumento dessa generalidade.

Schilder evoca o estatuto carnal do espelho em total independência de Wallon, e, pelas razões cronológicas evidentes, sem ter conhecimento do trabalho de Lacan. Ele o faz menos em uma perspectiva psicogenética do que para destacar uma caraterística permanente do esquema corporal. Schilder sublinha que o esquema corporal - ou a imagem do corpo, Schilder não distingue os dois - é e permanece inacabado ${ }^{35}$. Esta incompletude não é inicialmente de ordem escópica (o fato de que não vemos nosso corpo por inteiro, ponto sobre o qual insistia Wallon), ela não vê em primeiro lugar o conhecimento que temos de nosso corpo, mas afeta a estruturação identitária do esquema corporal - o que certos psicanalistas nomearão mais tarde "a imagem inconsciente do corpo". É verdade que "sou meu corpo", mas este ser é fundamentalmente inacabado, o que induz uma correlação secreta entre ser seu corpo e estar no mundo, ser para o outro. É uma das razões pela qual o "corpo próprio”, segundo Schilder, não é no fundo mais "próprio" que aquele de outrem: uma concepção da carne como se pertencendo e se conhecendo plenamente é ilusória, ela reprime aquele inacabamento e nega suas consequências intoleráveis. Uma outra consequência dessa incompletude constitutiva é o poder de fascinação que exerce sobre nós toda imagem do corpo - imagem entendida aqui em sentido próprio, escópico - a começar pelo espelho ${ }^{36}$.

Mesmo insistindo sobre nosso inacabamento, esta abordagem permanece externa ao drama da fragmentação e da alienação desenvolvido por Lacan. O último Merleau-Ponty, entre os dois, tende espontaneamente a privilegiar a perspectiva de Schilder, que termina por recobrir aquela de Lacan, embora importante nos cursos da Sorbonne. Por quê? A passagem precisa de Image and Appearance que inspira sua última reflexão sobre o espelho traz a resposta. Merleau-Ponty reencontra aí o espelho em um molde, não lacaniano, que lhe é familiar desde muito tempo: aquele de uma fenomenologia da percepção e da intersensorialidade estendida por Schilder até a intercorporeidade.

Um simples experimento pode enfatizar novamente que a comunidade entre o corpo-imagem fora e o corpo existe já na esfera da percepção.

Eu sento aproximadamente a três metros de distância de um espelho segurando um cachimbo ou um lápis em minha mão e olho no 
espelho. Eu pressiono firmemente meus dedos contra o cachimbo e eu tenho um claro sentimento cortante de pressão em meus dedos.

Quando eu olho atentamente a figura da minha mão no espelho, eu sinto agora claramente que a sensação de pressão não está apenas em meus dedos em minha própria mão, mas também na mão que está a três metros de distância no espelho. (...) Este sentimento não está portanto apenas em minha mão real, mas também na mão no espelho. Poderia se dizer que o modelo postural do corpo está também presente em minha figura no espelho. Ela não é apenas a figura óptica, mas também carrega consigo sensação tátil. Meu modelo postural do corpo está em uma figura fora de mim. Mas não é qualquer outra pessoa como uma figura de mim? ${ }^{37}$

Eu sinto o contato de meu charuto "em minha verdadeira mão assim como na mão do espelho": esta experiência vem embaralhar o corpo fenomenal e o corpo objetivo ${ }^{38}$, em uma comunidade efetiva entre meu corpo vivido e sua imagem "exterior"39. Que se passa? Há captação do corpo tátil e motor pela imagem visual, mas também, inversamente, polarização da visão pelo tocar. $\mathrm{O}$ esquema corporal evolui assim em uma espacialidade lábil, o corpo próprio está sempre ao mesmo tempo aqui e lá, capaz de sentir seu dentro no fora. Meu esquema corporal pode "se encontra[r] em uma imagem fora de mim" e, assim, em "cada ser humano". Estes fenômenos se apoiam sobre uma intersensorialidade e uma intermodalidade que enriquecem a intrasensorialidade, tornando-se o instrumento de uma intercorporeidade nascente.

$\mathrm{O}$ espelho de Metzger, fiel nisto a um dos principais eixos da Gestalttheorie, já evidencia a imbricação entre a percepção e a motricidade. $\mathrm{O}$ de Schilder vai nesta mesma direção, e revela uma forma de integração da reflexividade do tocar àquela da visão. A abertura do vidente-visível ao tocante-tocado, que se vê assim alargado a ponto de operar à distância, no espelho. Reciprocamente, as virtudes de proximidade, os poderes realizadores do tocar, são emprestadas à visão, que assim se torna palpação. A "palpação" faz parte dos temas bergsonianos de Merleau-Ponty que atravessam a redação do Visible et l'invisible. Quando este mesmo manuscrito, no último capítulo, afirma que "a visão é palpação pelo olhar", podemos agora compreender aquilo que esta célebre frase deve a Paul Schilder ${ }^{40}$. 
O exemplo do charuto no espelho é retomando e comentado por Merleau-Ponty em numerosas passagens dos manuscritos de 1960, que gravitam inicialmente em torno da preparação do curso de primavera sobre a Natureza, e depois pontuam as diferentes etapas de redação de L'Oeil et l'Esprit, que será terminado no mês de agosto. Seria fatigante retomar todos esses textos ${ }^{41}$. Citemos, no entanto, uma primeira amostra, extraída das folhas utilizadas pelo curso do Collège de France de 31 de março de 1960:

Captação do corpo tátil pela imagem visual: Schilder: eu sinto no espelho o contato do meu charuto sobre minha mão. Lugar do imaginário do ver: pelo ver e seus equivalentes táteis, inauguração de um dentro e de um fora e de suas trocas, de uma relação de ser com aquilo que, entretanto, está para sempre fora: a espacialidade do corpo é incrustação no espaço do mundo... ${ }^{42}$

Merleau-Ponty prossegue:

O esquema corporal como incorporação: o esquema corporal é isto.

Finalmente então (...) uma relação de ser entre meu corpo e o mundo, os diferentes aspectos do meu corpo, uma relação de projeçãointrojeção, uma relação de incorporação. Ele pode se estender para as coisas, (vestuário e imagem corporal), ele pode expulsar uma parte do corpo . Ele não é portanto feito de partes determinadas, mas ele é um ser lacunar (o esquema corporal oco por dentro) (...) A sensorialidade (sobretudo pela visão) implica intencionalmente a incorporação, isto é, um funcionamento do corpo como passagem a um fora, por seus 'orificios'. Outra consequência: como minha imagem capta meu tocar, a imagem visual dos outros o capta também: eles são assim o fora de mim. E eu sou seu dentro. Eles me alienam e eu os incorporo. ${ }^{43}$

Algumas semanas depois do fim do curso sobre a Natureza, MerleauPonty retoma novamente o fenômeno do cachimbo no espelho, ao longo de sucessivas versões de L'Oeil et l'Espritt4. Aqui está um trecho do primeiro esboço:

Schilder dizia que se eu fumo meu cachimbo diante de um espelho, eu sinto a superficie lisa e quente da brasa não apenas ali onde estão meus dedos, mas também lá, no espelho, nestes dedos apenas visíveis que 
carregam consigo tudo o que tocam os meus dedos de carne. Se há um fora do meu dentro, há um dentro de todos os outros corpos que eu vejo, eles são agora forrados de todo invisível de meu corpo, eles incorporam minha carne, e reciprocamente eu vivo meu corpo não apenas de acordo com aquilo que ele é, mas também de acordo com o que aprendo do espetáculo das outras vidas carnais, meu corpo se generaliza e comporta setores emprestados. Nós somos agora uns para os outros espelhos e, inversamente, o espelho reitera a cada instante para nós a operação mágica que faz com que o dentro e o fora passem um no outro... 45

A redação seguinte ${ }^{46}$ se aproxima do texto definitivo, que pode ser lido nas páginas 33 e 34 da edição francesa de L'Oeil et l'Esprit. Estas diversas versões marcam um ponto culminante da inspiração que Merleau-Ponty encontrou na abordagem schilderiana do esquema corporal. Além do fenômeno do cachimbo no espelho, a dívida de Schilder está lá condensada em uma espécie de síntese, orientada pela ênfase kleiniana sobre a incorporação. As afirmações se atropelam para formar um conjunto audacioso e ainda obscuro, onde pressentimos, contudo, que caminham as dimensões essenciais da filosofia do autor, tanto em seus horizontes antropológicos como ontológicos. Os horizontes justamente abertos por sua longa reflexão sobre o esquema corporal, a qual termina por manter como sinônimo "esquema corporal" e "carne".

Estes textos são atravessados por várias linhas de força, a começar por uma forma de habilitação da "incorporação" (esta troca do dentro e do fora) a uma "relação de ser". Esta relação encontra no espelho um de seus instrumentos privilegiados ("o espelho reitera a cada instante para nós a operação mágica que faz com que o dentro e o fora passem um no outro" 47 , "ele é o instrumento de uma universal magia que transforma (...) eu no outro e outro em mim" 48 ), não apenas no espelho de vidro mas, de modo mais amplo, naquele do vidente-visível: "Nós somos agora uns para os outros espelhos" 49 . Merleau-Ponty reúne aqui certos aspectos da compreensão, justamente estendida ao vidente-visível, que Françoise Dolto possuía do espelho lacaniano ${ }^{50}$ - suas trocas com Dolto talvez se orientem nesse sentido ${ }^{51}$, mesmo se a mediação primeira permanece ainda aquela de Schilder ${ }^{52}$. O espelho do vidente-visível conduz à 
expressão do "que tenho de mais secreto" 53 , ele "leva para fora os segredos da minha carne" e forra o corpo que vejo de "todo o invisível de meu corpo" 54 . O ser-no-mundo desdobrado pelo esquema corporal se revela assim integralmente sustentado por um regime de incorporação ("o esquema corporal como incorporação: o esquema corporal é isto"55) de início animado por um horizonte de uma intercorporeidade radical. E é justamente esta, por excelência, a "relação de ser": uma relação de "substância" afetando minha substância e aquela do outro ("minha substância passa neles"56, "meu corpo comporta os segmentos estrangeiros assim como os outros são feitos da minha substância"57), uma relação substancial que é também relação transubstancial, um acoplamento que é nutrição mútua.

Estas diversas linhas de força convergem assim em direção a uma dimensão última, flagrante: aquela do desejo, desde sua descrição estrutural topológica (o quiasma do dentro-fora, quase obsessivo nestes textos), sua descrição arqueológica psicanalítica, e justamente em seus horizontes mais oníricos ("o imaginário do ver"58) e ontológicos, atravessados pela negatividade - como o ser, o esquema corporal é lacunar, "oco por dentro"59.

\section{§ 4. A negatividade do espelho. Comentários conclusivos}

As diferentes versões de L'Oeil et l'Esprit são marcadas pela substituição sistemática, e definitiva, da "carne" no lugar de "esquema corporal" mesmo fazendo regularmente referência a Schilder, elas também nunca usam o termo "esquema corporal" (ou "imagem corporal"). "O fantasma atrás do espelho traga para fora minha carne"60, escreve assim MerleauPonty; de modo mais geral, "toda técnica" "figura e amplia a estrutura metafisica da nossa carne."61 Simetricamente, na preparação do curso sobre a Natureza da primavera de 1960, ou ainda nas notas inéditas sobre o corpo datadas do mesmo período, bastaria escrever "carne" no lugar de "esquema corporal" para encontrar algumas formulações posteriores a estas folhas. A conexão entre as duas noções - carne e esquema corporal - é também claramente indicada em várias passagens do curso de 1960, invadido pela figura do circuito $^{62}$. 
A eminente circularidade da incorporação foi introduzida desde L'homme et l'adversité (1951), na sequência das reflexões sobre o espelho expostas no curso sobre Les relations avec autrui chez l'enfant. Resposta aos dualismos do corporal e do espiritual, a carne, escrevia então MerleauPonty, é "relação de pessoa a pessoa (...) e não apenas a um outro corpo"; sustentada por sua dimensão "sexual-agressiva", ela é o lugar onde se tece "entre mim e outrem o sistema circular de projeções e de introjeções", onde se ilumina "a série indefinida de reflexos reflexionantes e de reflexos refletidos que faz com que eu seja outro e que ele seja eu-mesmo."63 Merleau-Ponty concluía: "Tal é a ideia (...) que o freudismo acaba por nos oferecer"64. Este ponto de chegada, generosamente emprestado de Freud, era antes um ponto de partida para a filosofia da carne de Merleau-Ponty, de início marcada por uma lógica do espelho que culmina, em 1960, nos textos que acabamos de ler.

Se a expressão "Eu-outro", para retomar o título de uma nota de trabalho célebre, é uma "fórmula insuficiente"65, é porque a carne não era só antes de ser com outrem. Não há solipsismo, mas um circuito originário em breve desenvolvido pelo espelho do vidente-visível, uma reflexão carnal que sempre traz em suas redes o mundo e outrem. Este circuito é mais aberto que aquele do tocante-tocado, suscetível de se fechar sobre si mesmo em uma reversibilidade narcísica mais imediata. Não existe o "espelho tátil", destaca Merleau-Ponty ${ }^{66}$. "O tocar se toca imediatamente (...) A visão rompe este imediato (o visível está à distância, fora dos limites do meu corpo) e restaura a unidade por espelho, no mundo."67

A reflexão carnal do vidente-visível me inicia ao outro no movimento mesmo pelo qual outrem me inicia a mim mesmo. Ela é assim perfeitamente estrangeira ao olho-espírito cartesiano tão hesitante em decidir se, sob o chapéu e o casaco que passam na rua, o boneco é um ser humano real. Visão hesitante em decidir se, vendo-se a si mesmo no espelho, o boneco é de fato... ele mesmo. Não sem ironia, Merleau-Ponty sublinha, com efeito, em diversos momentos, que um cartesiano aprova esta deficiência, como se ele sofresse de certas patologias descritas pela literatura neurológica moderna: "um cartesiano não se vê no espelho: ele vê um manequim, um "fora" do qual tem todas as razões de pensar que os outros o vêm paralelamente, mas que, não mais para si que para os outros, não é uma carne"68. Esta mesma ideia é retomada no curso sobre 
a ontologia cartesiana de 1961, e dá lugar a uma última evocação do espelho de Schilder ${ }^{6}$. Em conexão com sua crítica à concepção sartriana do imaginário, Merleau-Ponty afirma que Descartes retira a força da semelhança, reduz o imaginário a um analogismo formal estranho àquele da carne, e torna impossível a intercorporeidade.

Merleau-Ponty, como Dolto, amplia o fenômeno do espelho bem além do objeto espelho: o olhar do outro é espelho, os outros seres humanos são "espelhos para mim por seus corpos"70. Ainda de modo mais amplo, toda coisa é suscetível de ser espelho da minha carne, graças à "projeção antropológica" que atravessa de ponta a ponta nossa relação com o mundo. Simetricamente, minha carne torna-se ela mesma espelho do outro e do mundo: assombrado por um mundo que ela reveste de si mesma, a carne opera como um espelho ao fazer de toda coisa um espelho. E é justamente de acordo com o conjunto circular destas direções de sentido que "a carne é fenômeno de espelho".

Esta circularidade pode ser articulada com a delicada questão da negatividade da carne? Por um lado, Merleau-Ponty parece não alcançar as dimensões mais dialéticas, senão trágicas, do espelho lacaniano, e acentua o espelho como instrumento de unificação do esquema corporal. Por outro, compreendido nesta mesma perspectiva, ele insiste sobre o inacabamento essencial de nosso ser. O inacabamento, o inesgotável, mas não a destruição ou a loucura: uma negatividade que não visa o nada, mas cava nossa abertura ao ser, abertura aos outros seres lacunares e às lacunas do próprio ser. Isto indica já a natureza, como os limites, da negatividade merleau-pontyana - não sem coerência com a atitude crítica de Schilder face a face com a psicanálise freudiana, sublinhando nossa incompletude, ao mesmo tempo que recusa a hipótese de uma pulsão de morte.

De onde vem então nossa atração pelo espelho: para encontrar ou reencontrar nossa unidade, "completar nosso corpo"71, ou por que a carne tem necessidade "de se relacionar a uma outra coisa que sua própria massa"72? Ao insistir sobre a unificação pela intercorporeidade, os últimos textos sobre o espelho conjugam os dois, conjunção típica da abordagem de Schilder. Sempre lacunar, o esquema corporal não é um sistema fechado, mas, como a mão, um ser-estrelado que esposa o mundo em sua topologia aberta ${ }^{73}$. De modo que a circularidade da carne, para retomar algumas expressões recorrentes nos últimos manuscritos, é 
"circuito aberto"74, "circuito interminável"75, ou ainda "circuito externo"76. Circuito, a carne é mais exatamente pregnância, que porta outrem em si e já o engendra. Ela é esta estranha "coisa" que porta as coisas em seu circuito, e este "portar" faz carne tudo aquilo que toca a carne, até a carne da coisa e aquela do mundo. $\mathrm{O}$ espelho revela que o corpo percipiente e desejante demanda outra coisa que si mesmo para existir, e o demanda por sua própria condução, por sua própria inércia, até em suas involuções mais secretas.

Esta abordagem da carne não elimina a possibilidade do conflito e da violência. Ao contrário, é justamente por haver uma tal "situação comum" com outrem, uma tal "promiscuidade", que a transgressão é inevitável. Desde que outrem se intercala no circuito da minha carne, quer dizer desde sempre, ele transgride e aguça meu inacabamento. Trazido em minha carne desde a origem, outrem é desde o início o terceiro incluso em minhas involuções; mas, nascendo de mim, ele rasga a mim mesmo: o retorno a si do desejo é dobrado pela perda de si no outro, do rapto por um olhar estrangeiro. $\mathrm{O}$ inacabamento constitutivo do esquema corporal é, finalmente, uma raiz comum de duas figuras fundamentais da carne, a circularidade e a transgressão, que encontramos misturadas ao longo de todo o percurso de múltiplas entradas da intercorporeidade em Merleau-Ponty.

Enfim, a análise do espelho, como a da negatividade que ele traz à tona, trazem uma importante chave do espaço fenomenal. O espaço não está vazio de, não há o vazio da extensão cartesiana, perfeitamente desencarnada e des-engajada para ser o plano neutro das operações da consciência. Um plano construído para não ser espelho senão dessas operações mesmas, para ser espelho de tudo menos da carne.

O espaço seria então pleno, pleno de minha corporeidade, pleno de nossa intercorporeidade? Ele é, antes, implantado por ela, aberto pelo entrelaçamento da minha carne e da carne de outrem. Mais exatamente, ele é aberto por aquilo que abre a própria intercorporeidade, pelo inacabamento e pela interminável espera, inscritos na arquitetura de uma carne que arquiteta o mundo. Se o espaço não é vazio de, ele também não deve ser compreendido como sendo pleno de, mas como abertura, inaugurada pelo... inacabamento de nosso ser aberto às lacunas do ser: pela negatividade do desejo. Onde encontramos então um vazio totalmente 
diverso, não mais aquele que se construía para elidir outrem, se colocar ao abrigo dos problemas relacionais e dos riscos do desejo. "O esquema corporal é oco por dentro"77: tal qual revelada pelo espelho, a espacialidade da carne não é unicamente uma espacialidade positiva de investimento motor e desejante, de prolongamento, de generalização de si; ela é isso porque ela é também, e em primeiro lugar, espacialidade negativa, uma abertura que é em si mesma lacuna. O que permite que se compreenda melhor porque o espaço é decididamente antes de tudo, para Merleau-Ponty, profundidade - "\zç. o abismo, que cava tanto mais nosso desejo quanto ele é espelho de nosso ser lacunar.

${ }^{1}$ NT, p. 309. Cf. infra a lista de siglas utilizadas para designar os escritos de Merleau-Ponty. [Em virtude das referências do Autor a manuscritos de Merleau-Ponty, optou-se por manter o seu modelo de indicação bibliográfica. N.dosE.]

2 OE-ms [40]v(10).

${ }^{3}$ Natu3, p. 271/[37].

${ }^{4}$ Les origines du caractère chez l'enfant. Les préludes du sentiment de personnalité, Paris, Boivin et Cie, 1934 ; retomada em P.U.F., 1949.

5 Cf. É. Jalley, Wallon et la psychanalyse, Bibliothèque des thèses de La Sorbonne, 1986 ; Freud, Wallon, Lacan. L'enfant au miroir, Paris, E.P.E.L., 1998. Cf. também É. Roudinesco, Jacques Lacan. Esquisse d'une vie, histoire d'un système de pensée, Paris, Fayard, 1993.

${ }^{6}$ Cf. CDU(RAE), pp. 188/41 sq. ; Sorb(RAE), pp. 314 sq. ; Sorb(MPE), pp. 525 sq.

7 Cf. Les origines du caractère chez l'enfant, 1934, notadamente pp. 190-207. Cf. também « Comment se développe chez l'enfant la notion de corps propre ", Journal de Psychologie, nov.déc. 1931, pp. 705-748.

8 Intervenção de Lacan sobre a exposição de Marie Bonaparte, "Vistas paleobiológicas e biopsíquicas ", revista Francesa de Psicanálise, 3, 1938, p. 551. Lacan expõe sua teoria pela primeira vez em 16 de junho de 1936 diante da Sociedade Psicanalítica de Paris, em seguida, tenta em vão introduzi-la no décimo quarto Congresso Internacional de Psicanálise realizado em Marienbad, em 3 de agosto, intitulado "O Estádio do Espelho. Teoria de um momento estruturante e genético da constituição da realidade, concebida em relação com a experiência e a doutrina psicanalítica". Em 1938, ele inclui esta temática no artigo "A família” que Wallon lhe pediu para redigir para a Encyclopédie française. Ele a retoma em 1946 nas Jornadas psiquiátricas de Bonneval ("Propos sur la causalité psychique ", in Le problème de la psychogenèse des névroses et des psychoses, Paris, Desclée de Brouwer,1950, reimpresso em Escritos, Paris, Seuil, 1966, p. 151-193), depois no XVI Congresso Internacional de Psicanálise Internacional, Zurique, 17 de julho de 1949: "O Estádio do Espelho como formador da função do Eu tal 


\section{8}

como ela é revelada na experiência psicanalítica" (Revue française de Psychanalyse, $n^{\circ} 4$, outubro-dezembro 1949 ; cf. Écrits, op. cit.).

${ }^{9}$ Lacan divide o Estádio do Espelho em três etapas principais. A criança inicialmente percebe seu reflexo como um ser real de carne e osso, que ele busca apreender ou aproximar. Em uma segunda etapa, ele entende que este reflexo é apenas uma imagem e não um ser real, mas ainda não o reconhece como seu; ele já não tenta agarrá-la ou tocá-lo, tendo compreendido o aspecto virtual do espaço por trás do espelho. Finalmente, em uma terceira fase, ele compreende que esta imagem é sua imagem, que ela o representa. Esta conquista gradual da unidade e da identidade se liga assim ao [denso] nó do real, do imaginário e do simbólico.

10 Cf. « Le stade du miroir comme formateur de la fonction du Je... », art. cit., p. 94.

11 Cf. Freud, Wallon, Lacan. L'enfant au miroir, op. cit., pp. 38-39.

12 Cf. Sorb(EVA) 96, 112-113, CDU(RAE) 202-204/55-58, Sorb(RAE) 318-319.

13 Cf. Sorb(RAE), p. 318.

14 [N.T.] Seguindo aqui as recomendações do próprio SAINT AUBERT, traduzimos "empiétement" por transgressão, mantendo a compreensão de que este termo envolve simultaneamente a ideia de transgressão (de um lugar, um limite, uma fronteira) e de invasão (no interior de), abarcando também sua dimensão de agressão e violência.

15 Cf. Sorb(EVA), pp. 112-113.

16 Uma psicanalise existencial da qual ele faz oposição desde os Causeries de 1948, a conferência sobre L'homme et l'objet dada no mesmo ano, et as conferências do Mexico do início de 1949.

17 Cf. CDU(RAE) 205/58, Sorb(RAE) 319.

18 MSME, p. 159/[125](XIII7-XIV1).

19 Cf. notadamente MSME 182/[176](5), 183/[176]v(6) e 189/[181](1).

${ }^{20}$ Frankfurt am Main, W. Kramer, 2e éd. 1953, 471 pp., versão consideravelmente ampliada em relação à primeira edição (1936).

21 Cf. EM3 [239](15)-[248](34), abril-maio 1960.

22 Op. cit., chap. IX, pp. 213-215.

23 Op. cit., pp. 213-214.

24 Op. cit., p. 215.

25 Ibid.

26 Cf. PhP, pp. 236-237.

27 "A sombra de um cubo de arame - O que eu vejo? A carne do cubo. A percepção é sem what. Pelo movimento da sombra, ela deixa de ser sombra (cf. sombra figurativa) e torna-se um cubo que west $\mathrm{O}$ objeto estranho no arame: que queremos dizer ao dizer que o vemos, 
ainda que não possamos defini-lo, e nem designá-lo? "(EM3 [254], maio de 1960)" A Sombra de um dado de arame - Que é o dado, o cubo? O que é que vê um cubo? O cubo Selbstgegeben - O sentido do cubo e da carne do cubo - o cubo como horizonte - As relações da sombra com a coisa - a sombra está no imaginário? Não - Está no real? Estrutura movimento e estrutura coisa: quando a sombra do cubo de arame é posta em movimento, há a aparição de um cubo sobre a tela (e não mais uma sombra de cubo) - A "realidade" = a produtividade fenomenal. O objeto de arame girando: analisar a "constância" de sua forma - que não se trata da constância ideal e nem da constância real ("imagem visual") (...). A estrutura coisa imagem em espelho $=$ a imagem em espelho do cubo girando fora do espelho e passa no cubo: com deformação (encolhimento) - O Ser-imagem -Neste exemplo, mostrar em que sentido a percepção contém sua verdade "(EM3 [242] (22), em abril ou maio 1960). "Silêncio da percepção $=$ o objeto de arame do qual não saberia dizer o que ele é, nem quantos lados ele tem etc., e que entretanto está lá (é o critério mesmo do observável segundo Sartre que é aqui contradito, - e o critério do imaginário segundo Alain, que intervém na percepção). "(NT, p. 322, novembro 1960).

28 Merleau-Ponty já encontrava exemplos análogos no estudo de Michotte sobre La perception de la causalité, que também destacava como o o objetivo se anima (se animaliza) no movimento. Cf. A. Michotte, La perception de la causalité, Paris,Vrin, 1946 ; Anvers-Bruxelles-GandLouvain-Amsterdam, Publications universitaires de Louvain, Éditions Érasme et Standaard-Boekhandel, 1952.

29 Cf. E. de Saint Aubert, Du lien des êtres aux éléments de l'être, Paris,Vrin, 2004, pp. 137-146.

30 Cf. Du lien des êtres..., op. cit., pp. 255-270.

31 Cf. nosso artigo « Space and the Body Image in Merleau-Ponty's Philosophy Of the Flesh ", in Graduate Faculty Philosophy Journal (The New School for Social Research, New York), Volume 30, Number 1, 2009, pp. 31-58.

32 The Image and Appearance of the Human Body : Studies in the Constructive Energies of the Psyche, Londres, K. Paul, Trench, Trubner, 1935 ; New York, International Universities Press, 1950 (edição indicada IAHB) ; L'Image du Corps. Étude des forces constructives de la psyché, trad. F. Gantheret et P.Truffert, Paris, Gallimard, 1968 (edição indicada IC).

33 Não se trata de negar, bem entendido, a influência do famoso tocante-tocado do Ideen II, sobre a qual tanto se escreveu, mas de contextualizá-la, de lhe dar sua justa medida. Pouco abordado na Phénoménologie de la perception, este motivo não será retomado senão bem mais tarde, em uma perspectiva nova e não husserliana: aquele do vidente-visível (recusado, como se sabe, por Husserl), elaborado diretamente a partir do espelho de Wallon e Lacan (e não em uma releitura de Husserl), e em parte orientado contra Sartre. Nós desenvolvemos esse assunto em detalhe em um livro em preparação.

34 OE, p. 33.

35 Cf. p. ex. IAHB, p. 287 (IC, p. 299).

36 «Nosso corpo não é de modo algum melhor conhecido por nós do que os corpos dos outros. Não deveríamos usar o espelho tão avidamente como se fosse o contrário. O interesse que temos nos espelhos é a expressão da labilidade de nosso próprio modelo postural do 
corpo, da incompletude dos dados imediatos, da necessidade de construir a imagem do nosso corpo em um esforço construtivo contínuo. » (IAHB, p. 273 / IC, p. 285)

37 IAHB, pp. 223-224 / IC, pp. 239-240.

38 «Eliminação da alternativa: mundo objetivo e mundo fenomenal: as estruturas do fenomenal se reencontram, no «objetivo» («a imagem»). Isto aplicável ao corpo (...) O corpo estesiológico mediador dessa identificação. Fenomenal e objetivo «embaralhados» (N-Corps [84](1)).

39 Encontramos em Husserl alguns textos sobre o espelho, dos quais Merleau-Ponty não tinha conhecimento, que são relativamente próximos daquele de Schilder. Cf. em particular Hua XIII, $\mathrm{n}^{\circ} 12$, p. 327. Cf. Natalie Depraz, Transcendance et incarnation. Le statut de l'intersubjectivité comme altérité à soi chez Husserl, Paris,Vrin, 1995, pp. 149-151.

40 Cf.VI4, pp. 173-177. Cf. aussi VI3, p. 170.

41 Cronologicamente, o primeiro texto que evoca o exemplo do charuto no espelho se encontra nas notas de leitura de Schilder: «A pressão de meus dedos sobre o charuto no espelho (223). Então, como os espelhos são espelhos de mim, reciprocidade de meu esquema corporal e do dele (...) meu esquema corporal vai até o espelho" (N-Corps [105]v) MerleauPonty volta sobre este exemplo na folha [84](1), sobre a qual se apoia manifestamente a preparação do curso de 31 de março de 1960.

42 Natu3, pp. 345-346/[73]v.

43 Natu3, p. 346/[73]v-[74].

44 Temos aqui uma boa ilustração do paciente trabalho de escrita do qual este ensaio, particularmente elaborado, foi fruto. Jamais insistiremos o suficiente sobre o estatuto capital de L'Oeil et l'Esprit, verdadeiro testamento ontológico involuntário de Merleau-Ponty. Vejamos um extrato da fase programática deste ensaio: "II 1) Mundo mágico da imagem, da semelhança, da analogia. O espelho: no mundo vivido: ele completa meu corpo visível, faz com que eu me veja verdadeiramente, de fora, como os outros me veem, que eu sinta nos outros meu corpo tátil (Schilder), que os outros sejam espelhos de mim e eu deles, que haja concentração e relações expressivas." (OE-ms [147])

45 OE-ms [16](13)-[16]v(14).

46 OE-ms [40]v(10).

47 OE-ms [16]v(14).

48 OE, p. 34.

49 OE-ms [16]v(14).

50 Cf. p. ex. F. Dolto e J.-D. Nasio, L'enfant du miroir, Paris, Payot \& Rivages, 2002, pp. 58-59. Françoise Dolto, à quem devemos o testemunho escrito mais precoce sobre o Estádio do Espelho em Lacan, dois anos antes mesmo que este último tivesse publicado qualquer coisa sobre o tema, integrará por sua vez este Estádio em um sistema alargado que lhe respeita o sentido profundo. Desde sua tese (Psychanalyse et pédiatrie, tese defendida em julho de 1939), e de maneira ainda mais focada em seu longo estudo L'image inconsciente du corps (Paris, Seuil,

doispontos, Curitiba, São Carlos, vol. 9, n. 1, p.11-33, abril, 2012 
1984), Dolto situa a prova do espelho como sendo uma das "castrações 'symboligènes"” que pontuam a história de maturação de um indivíduo.

51 Merleau-Ponty, que evoca os trabalhos de Dolto em seus cursos da Sorbonne, teve também a ocasião de encontrá-la pessoalmente. Nós agradecemos Catherine Dolto por seu testemunho a este respeito.

52 «Nossos olhos e os olhos dos outros tornam-se instrumento principal das relações entre as imagens dos corpos» (IC, p. 252 / IAHB, pp. 237-238)

53 OE, p. 33.

54 OE-ms [40]v(10).

55 Natu3, p. 346/[73]v.

56 OE, p. 34.

57 OE-ms [40]v(10). Cf. também PM, p. 187 : « este outro é feito de minha substância».

58 Natu3, p. 345/[73]v.

59 Natu3, p. 346/[73]v.

60 OE, p. 33.

61 Ibid.

62 Cf. notadamente Natu3, pp. 285-286/[46].

63 S(HoAdv), p. 292.

64 Ibid.

65 NT, p. 274, novembro 1959.

66 Natu3, p. 345/[73]v.

67 Ibid.

68 OE, pp. 38-39. Um cartesiano não pode senão reduzir «sua 'imagem' no espelho» à «um efeito da mecânica das coisas; se ele a reconhece, se ele a considera "semelhante", é seu pensamento que tece essa ligação, a imagem especular não é nada dele» (OE, p. 39). Cf. aussi OEms [18]v(18), [41](11), [155].

69 Cf. OntoCart, p. 177/[11](11), NTontocart [115]-[116], [117], [121].

70 OntoCart, p. 177/[11](11).

71 «Porque nós construímos os espelhos: para nos ver, converter o vidente em visível, completar nosso corpo.» (NTontocart [117], curso de 2 de fevereiro 1961)

72 Natu3, p. 271/[37].

73 «O corpo libidinal e a 'intercorporeidade. Isto = Einfühlung corpo-coisas, penetração à distância dos sensíveis por meu corpo. As coisas como o que falta ao meu corpo para fechar seu circuito. Mas isto é também uma abertura do meu corpo aos outros corpos.» (Natu3, p. 281/[43]v).

doispontos, Curitiba, São Carlos, vol. 9, n. 1, p.11-33, abril, 2012 


\section{2}

74 Cf. Natu3 p. 279/[43], OE-ms [40](9), OE p. 33.

75 «O corpo abre se sentindo o circuito interminável do si e das coisas» (OE-ms [12]v(6)).

76 Cf. Natu3 331/[66]v, 333/[67].

77 Natu3, p. 346/[73]v.

\section{Lista de siglas (escritos de Merleau-Ponty)}

CDU(RAE): versão do Centre de Documentation Universitaire de la Sorbonne da primeira parte (1950-1951) do curso sobre Les relations avec autrui chez l'enfant (ver também Sorb(RAE)) ; retomada em Parcours 1935-1951, Lagrasse, Verdier, 1997.

EM: Être et Monde (inédit, B.N.F., volume VI) ; EM1 : essencialmente outono de 1958, algumas folhas de março de 1959 ; EM2 : diversas sequências de trabalhos distribuídas no ano de 1959 ; EM3 : essencialmente abril-maio de 1960, algumas revisões em outubro de 1960.

MSME: notas de preparação do curso no Collège de France de 1953 sobre Le monde sensible et le monde de l'expression, Genève, MétisPresses, 2011.

N-Corps: Notes sur le corps (1956-1960, sobretudo 1960), inéditas. B.N.F., volume XVII.

Natu3: notas de preparação do curso de 1960 sobre Nature et Logos : le corps humain, publicadas em La Nature. Notes, cours du Collège de France, Paris, Seuil, «Traces Écrites », 1995.

NT: notas de trabalho editadas por Claude Lefort na sequência do Visible et l'invisible, Paris, Gallimard, 1964.

NTontocart: ver OntoCart

OE: L'Oeil et l'Esprit (julho-agosto 1960), Paris, Gallimard, 1964 ; « Folio essais», 1985 (citamos esta edição).

OE-ms: notas de leitura, de preparação e diferentes versões manuscritas inéditas de L'Oeil et l'Esprit (printemps et été 1960). B.N.F., volume V. 
OntoCart: notas de preparação do curso no Collège de France de 1961 sobre L'ontologie cartésienne et l'ontologie d'aujourd'hui, publicadas em Notes de cours 1959-1961, Paris, Gallimard, 1996 ; NTontocart : notas de trabalho inéditas acompanhando a preparação do curso, B.N.F., volume XIX.

PhP: Phénoménologie de la perception, Paris, Gallimard, 1945.

PM: La prose du monde, Paris, Gallimard, 1969.

S(HoAdv): «L'homme et l'adversité » (setembro 1951), in Signes, Paris, Gallimard, 1960.

Sorb: Merleau-Ponty à la Sorbonne, résumé de cours 1949-1952, Grenoble, Cynara, 1988 ; Sorb(EVA) : L'enfant vu par l'adulte (1949-1950) ; Sorb(MPE) : Méthode en psychologie de l'enfant (1951-1952); Sorb(RAE): Les relations avec autrui chez l'enfant (1950-1952).

VI: Le visible et l'invisible, Paris, Gallimard, 1964 ;VI1: Réflexion et interrogation (março-abril 1959);VI2: Interrogation et dialectique (marçoabril 1959);VI3: Interrogation et intuition (novembro 1960);VI4: L'entrelacs - le chiasme (novembro 1960). 
$\bullet$ 